\title{
A CONSTITUIÇÃO DE UM LOCUTOR COMO IDOSO: UMA ANÁLISE ENUNCIATIVA
}

AdÉlli Bortolon BAZZA* (PG-UEM)

PEDRO NAVARRO $^{* *}(\mathrm{UEM} / \mathrm{CNP} \mathrm{Q})$

\section{RESUMO}

As discussões apresentadas neste artigo têm como objetivo analisar a identificação (ou não) de um locutor com a posição-sujeito de idoso. Como corpus de análise foi selecionada uma entrevista veiculada no site Portal do Envelhecimento, na qual a organizadora de um livro expõe o trabalho de elaboração da obra, cuja temática centra-se em questões relativas à velhice. A análise foi embasada nos Estudos Enunciativos, a partir de propostas de Benveniste $(1989,1995)$ e de Guimarães $(1989,1995,1996,2005)$. Esse aporte teórico permitiu observar como se dá, ao longo do texto da referida entrevista, a instauração das pessoas da enunciação. Para tanto, a entrada linguística neste material se deu pela observação dos pronomes pessoais utilizados, os quais permitiram estabelecer a autora entrevistada como foco e, portanto, como locutora principal. Em relação às demais pessoas instauradas nesse processo enunciativo, a entrevistadora constituiu-se como o tu e o idoso como o ele. Em linhas gerais, a análise apontou para as seguintes considerações: a) na fala da enunciadora, há um apagamento do $t u$ e uma alternância entre $e u$ e nós para se referir à primeira pessoa; b) o uso do nós, em algumas situações, junta a locutora ao grupo que colaborou na confecção do livro e em outras é indeterminado, o que permite a interpretação do ele (idoso) como incluso; c) tal utilização dos pronomes demonstra que a locutora constrói uma identificação apenas implícita à posição-sujeito idoso.

PalaVRAS-ChaVE: Locutor, Idoso, Enunciação, Posição-Sujeito.

* Doutoranda em Estudos Linguísticos pelo Programa de Pós-Graduação em Letras da Universidade Estadual de Maringá (UEM), Maringá, Paraná, Brasil. E-mail: adellibazza@hotmail. com.

** Doutor em Linguística e Língua Portuguesa, professor do Departamento de Língua Portuguesa e do Programa de Pós-Graduação em Letras da Universidade Estadual de Maringá. (UEM), Maringá, Paraná, Brasil. E-mail: navarro.pl@gmail.com. 


\section{INTRODUÇÃO}

Na última década, começou-se a discutir o envelhecimento da população. Falar sobre isso se tornou bastante urgente, primeiro em países europeus, que começaram a constatar o chamado envelhecimento da população, ou seja, o aumento do número de idosos na população geral há cerca de dez anos. Como resposta a tal demanda, a União Europeia, há algum tempo, já criou propostas de ação. A Comissão de 12 de Outubro de 2006, intitulada O futuro demográfico da Europa - Transformar um desafio em oportunidade "formulou várias recomendações que se baseiam designadamente na Estratégia de Lisboa renovada, a fim de melhor tirar partido das oportunidades de uma vida mais longa, mas igualmente de iniciar uma renovação demográfica"1. Apesar de, inicialmente percebido na Europa, esse fenômeno foi comprovado no Brasil por dados do Censo 2010², segundo o qual "o índice de envelhecimento aponta para mudanças na estrutura etária da população brasileira", constatando, portanto, um aumento das pessoas dessa faixa etária em relação à população total do país.

Credita-se esse fato, entre outros fatores, ao avanço das pesquisas médicas que garantem maior longevidade às pessoas. Tal mudança no perfil da população afetou diversos segmentos que tiveram de se adaptar a essa nova realidade. No campo político, surgiram políticas de atenção ao idoso, como a implantação do Estatuto do Idoso, as ATIs (academias da terceira idade), o programa Viaja Mais Melhor Idade, a revisão das regras da Previdência Social, entre outros. O campo acadêmico ressoou essa mudança social, com o desenvolvimento de pesquisas sobre os idosos e o envelhecimento, principalmente nas áreas da saúde e sociais. $\mathrm{O}$ mercado de consumo aumentou a oferta de produtos específicos para essa faixa etária. E a mídia refletiu essa realidade, ao conceder maior espaço a esses sujeitos, seja como personagens de programas e publicidades, seja como tema de debates.

Esse contexto demonstra que questões relacionadas ao idoso tornaram-se uma das demandas sociais a serem atendidas no momento, o que acarretou que ele fosse tema de uma grande confluência de enunciados. Os estudos contemporâneos sobre a linguagem apontam que, mais que a simples descrição de uma realidade, o funcionamento da linguagem permite a criação de efeitos de sentido responsáveis por 
constituir, ao mesmo tempo em que descrevem os elementos de que falam. Isso justifica a relevância de se questionar a imagem de idoso que vem sendo difundida e as implicações de sua circulação ${ }^{3}$.

Para embasar uma análise dessa natureza, é necessário extrapolar a visão da língua como forma e considerar a exterioridade que a compõe, principalmente a subjetividade que lhe caracteriza e que a permite constituir os sujeitos que falam e de quem se fala por meio dela. Após um longo período em que os estudos linguísticos focaram apenas a forma, demarcando a chamada Linguística Imanente, abriu-se uma nova perspectiva, com as propostas de Benveniste, que culminaram na formação de um campo denominado Teoria da Enunciação. Por se tratar de um campo que envolve grande variedade de autores e teorias, a análise é desenvolvida, a partir de elementos fundadores da teoria de Benveniste, associados a alguns conceitos discursivos, a exemplo de pesquisas realizadas por Guimarães $(1996,2005)$.

Tendo em vista que a proposta deste artigo é discutir a constituição de um locutor como idoso ou não, recortou-se para análise uma entrevista divulgada em 12 de dezembro de 2012 no site Portal do Envelhecimento ${ }^{4}$. Esse enunciado faz parte da série enunciativa, a partir da qual se desenvolve a pesquisa de doutorado, intitulada Subjetivação no discurso de sujeitos idosos em contexto de estudos na UNATI-UEM, desenvolvida por Bazza. No enunciado analisado, a socióloga Lúcia Ribeiro fala sobre o livro Um outro envelhecer é possível, lançado pela Editora Ideias \& Letras. Trata-se de uma coletânea em que pessoas diversas discutem a temática do envelhecimento. A análise parte, na materialidade linguística, da verificação de uma alternância entre o uso dos pronomes eu e nós pela autora para se referir a si e de uma neutralização do $t u$ e do ele. Propõe-se analisar como o emprego desses pronomes e a consequente instauração de pessoas do discurso podem produzir efeitos de aproximação ou de distanciamento entre entrevistado e idoso.

O desenvolvimento dessa discussão prevê algumas etapas: descrever, com base em elementos da enunciação, os sujeitos que figuram como eu, tu e ele nesse enunciado; confrontar o uso de eu/ nós, de modo a problematizar que pessoas compõem o sujeito quando pluralizado; discutir os efeitos de sentido resultantes da inclusão ou não 
dos idosos nesse nós. Por último, o texto formula uma hipótese sobre a questão da subjetivação do idoso, arriscando uma breve incursão nesse campo de pesquisa, o que deixa aberta uma discussão que aproxima a visada enunciativa de uma perspectiva discursiva.

\section{TEORia EnUnCIATIVA}

Os estudos de Benveniste retomam a tradição estrutural de observação dos fatos linguísticos. Essa retomada, no entanto, não se faz sem uma problematização que abarca a subjetividade na linguagem. A partir da observação dos dêiticos, ou seja, formas da língua que remetem à enunciação, rompe-se a hegemonia da significação interna do sistema linguístico e se abre o caminho para o sujeito, ao se destacar elementos que remetem ao exterior. Segundo Possenti (1988, p. 48), "A linguística enquanto estudo das formas exclui a enunciação e o discurso, como não pertinentes; ao contrário, a teoria da enunciação inclui também o enunciado e a língua". Benveniste propõe um estudo da língua e de sua sistemática, tal como era visto em sua época, porém relaciona esse sistema (seu uso e sua constituição) à compreensão do uso da linguagem. O diferencial de sua proposta em relação aos estudos linguísticos imanentes ${ }^{5}$ está na importância dada ao sentido. Nessa proposta, forma e sentido não se excluem.

A perspectiva de entendimento de língua de Benveniste se diferencia da de Saussure, uma vez que a vê como essencialmente social. De acordo com o teórico da enunciação (1989, p. 63), “A língua constitui o que mantém juntos os homens, o fundamento de todas as relações que por seu turno fundamentam a sociedade." Essa compreensão de língua, mostrada por Benveniste, também vai refletir na concepção de linguagem que defende. Para o autor, ela é o lugar onde o indivíduo se constitui como falante e como sujeito.

Em seu texto "Da subjetividade na linguagem", Benveniste inicia sua reflexão sobre a possibilidade de a língua ser um instrumento de comunicação, concepção de linguagem bastante corrente no momento em que ele escreve. Após elencar algumas evidências em favor dessa definição, o autor afirma que a linguagem não pode ser vista como um instrumento, tendo em vista que "a linguagem está na natureza do homem 
que não a fabricou", ao contrário "é a própria linguagem que ensina a definição do homem" (BENVENISTE, 1995 p. 285). Ao se distanciar da concepção de linguagem corrente na época, Benveniste abre mão de uma visão de língua independente do sujeito e passa a analisar as possibilidades que a própria língua oferece para que o sujeito se coloque e se marque nela. Enquanto nas perspectivas anteriores deixavam o indivíduo à margem da linguagem. A proposta de Benveniste é uma ideia de linguagem que dê ao indivíduo o status de sujeito.

Para o autor (1995), uma distinção a ser feita é entre enunciação e enunciado. Aquela seria o ato de produção de textos, enquanto este constitui o resultado dela. Desse modo, a enunciação é compreendida como um processo pelo qual o locutor faz uma apropriação da língua para falar, ele a mobiliza por sua própria conta, portanto a enunciação está ligada à língua. Para ele, a enunciação é constituída por parâmetros que permitem a comunicação, concebidos como o locutor, o interlocutor, o lugar e o tempo. Segundo Barbisan (2007, p. 28), "O produto desse ato é o enunciado, cujas características lingüísticas são determinadas pelas relações que se estabelecem entre o locutor e a língua. [...] A enunciação converte a língua em discurso pelo emprego que o locutor faz dela. Desse modo, a língua se semantiza”.

A subjetividade, inerente à língua, marca-se por meio de elementos linguísticos, por isso o princípio básico da subjetividade reside na "capacidade do locutor se colocar como sujeito" (BENVENISTE, 1995, p. 286). Segundo o autor (1995, p. 290), "a instalação da 'subjetividade' na linguagem cria na linguagem e, acreditamos, igualmente fora da linguagem, a categoria de pessoa". Os indivíduos se convertem em locutores da enunciação, no momento em que se denominam como eu e, consequentemente, instauram um $t u$. Ao se apropriar do aparelho formal da língua, o locutor enuncia sua posição com marcas linguísticas específicas, já predefinidas pela língua. A categoria de pessoa se marca, entre outros recursos, pelos pronomes de $1^{\mathrm{a}}$ e $2^{\mathrm{a}}$ pessoas $(\mathrm{eu}$ e $t u$, respectivamente) que designam os protagonistas da enunciação. É por ela que se instaura o discurso e, sem ela, a língua é apenas sistema de signos.

Benveniste considera a existência de dois grupos de elementos linguísticos: os dotados de sentido e os vazios de sentido. O primeiro faz referência a elementos do mundo, enquanto o segundo aponta 
para elementos recuperáveis apenas pela enunciação. Os termos que compõem este grupo são chamados linguisticamente de dêiticos, entre os quais estão muitos pronomes. Em seu texto A Natureza dos Pronomes, Benveniste (1995, p. 279) considera que "o problema dos pronomes é simultaneamente um problema de linguagem e um problema de línguas", pois esses elementos permitem que a língua se atualize em fala para um locutor. Entretanto, não caracterizam um locutor em específico, pois em cada enunciação o elemento $e u$ aponta um locutor diferente. Por conta dessa peculiaridade, "os pronomes pessoais são o primeiro ponto de apoio para o esclarecimento da subjetividade" (BENVENISTE, 1995, p. 288).

No processo dialógico instaurado, os sujeitos tomam consciência de si mesmos, a partir de um contraste: "Eu não emprego eu a não ser dirigindo-me a alguém, que será na minha alocução um $t u$ " (BENVENISTE, 1995, p. 286). Assim, o fundamento linguístico da subjetividade se dá por uma realidade dialética envolvendo o eu e o outro, definindo-os numa relação mútua. Essa relação é pautada em uma assimetria, pois, ao se instaurar como eu, o sujeito assume a voz e direciona a comunicação. $\mathrm{O} e u$ transcende ao $t u$, pois o primeiro só precisa tomar a palavra, enquanto o segundo precisa antes ser instituído como tu pelo eu. Nesse sentido, para o autor (1995, p. 286-287), “ego tem sempre uma posição de transcendência quanto a tu, apesar disso, nenhum dos dois termos se concebe sem o outro; são complementares, mas segundo uma oposição 'interior/exterior', e ao mesmo tempo são reversíveis".

Os elementos como o eu e o tu constituem o que o autor nomeou aparelho formal da enunciação. Nessa constituição, os dois primeiros elementos seriam pessoas do discurso que interagem entre si alternando o papel de locutor - interlocutor, por isso, elas são instâncias discursivas antes de serem instâncias linguísticas. Essas formas linguísticas estão sempre ancoradas na situação de enunciação, por isso são chamadas de vazias de sentido. Segundo Benveniste (1995, p. 282), um fato fundamental é o de "essas formas 'pronominais' não remeterem para a 'realidade' nem para posições 'objetivas' no espaço ou no tempo, mas para a enunciação sempre única, que as contêm”.

Em outra dimensão, ele seria a pessoa/objeto de que(m) se fala. De acordo com o autor (1995, p. 250), “A forma dita terceira pessoa 
comporta realmente uma indicação de enunciado sobre alguém ou alguma coisa, mas não referida a uma pessoa específica". Desse modo, ela opera como substitutivo abreviativo e pode representar sintaticamente um elemento ou todo o enunciado, com vistas à economia linguística. Diferentemente de $e u$ e $t u$, não aponta para si mesmo, nem para o interlocutor, mas para uma situação objetiva, por isso constitui a chamada terceira pessoa ou a não-pessoa. Segundo as postulações do autor, são pessoas do discurso eu/tu, enquanto ele está fora dessa ação dialógica. As primeiras constituem lugar de presença na enunciação e a última, o lugar da falta.

Ainda tratando das pessoas do discurso, Benveniste voltase às pessoas do plural: nós, vós. Segundo a teoria da enunciação de Benveniste, o nós não condiz com o plural de eu, nem o vós consiste em um plural de $t u$. O que acontece é a união de um eu com um não-eu. De acordo com Flores et al. (2008, p. 79), "Tanto o uso de nós se amplifica em uma pessoa mais solene, com maior autoridade no nós majestático, quanto se amplifica em uma pessoa mais difusa, com contornos indefinidos no nós de orador ou de autor. A mesma análise é feita para vós, tanto no uso coletivo quanto no uso de polidez a passagem do tu ao vós exprime pessoa generalizada".

Para Benveniste, a língua é produtora de mensagens, ao mesmo tempo em que é um sistema linguístico, no qual cada elemento se define pela relação que estabelece com os demais. Nessa perspectiva, o sujeito usa da língua para suas atividades de comunicação e marca sua subjetividade, apenas por meio dos elementos que a língua lhe oferece. Recentemente, devido ao contato das pesquisas de orientação enunciativa com outras áreas, como a pesquisas de natureza discursiva, isso passou a ser questionado. Possenti (1988, p. 49), por exemplo, pondera: "deve-se conceber a atividade do falante não como atividade de apropriação porque, a partir desse conceito, fica excluído o fato de que o locutor age também sobre a língua, já que põe em evidência apenas a ação entre e sobre os interlocutores através da língua”. Ao atuar sobre a língua, o sujeito se marca, mesmo quando não há um elemento linguístico destinado para isso.

Entre os autores que atualmente, desenvolvem pesquisas de natureza enunciativa, pode-se destacar Guimarães (1996), o qual se coloca 
no campo dos estudos enunciativos de filiação benvenisteana, embora desloque alguns conceitos, entre eles o de enunciação. Absorvendo as noções discursivas como a de interdiscurso, o autor (1996, p. 101) define a enunciação como "o pôr-se a língua em funcionamento movimentada pelo interdiscurso, quando alguém ocupa aí uma posição sujeito".

Guimarães (1989, p. 90) define sua concepção de interdiscurso, ao afirmar que ele "é a relação de um discurso com outros discursos, no sentido de que esta relação não se dá a partir de discursos empiricamente particularizados a priori. São elas próprias, as relações entre discursos, que dão a particularidade que constitui todo discurso". E neste "Ele se apresenta como séries de formulações distintas e dispersas que formam em seu conjunto o domínio da memória”. Zandwais (2011, p. 21) considera que o viés adotado por Guimarães não permite "pensar o espaço da enunciação como um lugar de representação descolado da emergência do acontecimento e de agenciamentos políticos, porque há sempre um espaço de identificação entre o dizer e papéis enunciativos, lugares sociais, regimes de verdade e posições que o sujeito assume em virtude dos lugares que ocupa".

O sujeito se constitui assim não só por se nomear como ego, tal como propunha Benveniste, mas por enunciar a partir da língua, por seu enunciado significar com base em saberes partilhados por meio dela e por ocupar um lugar em relação a essa teia que ele movimenta e na qual se insere. Segundo Guimarães (1996, p. 102), "identificar-se como sujeito é: sempre, estar dividido entre o que se supõe saber sobre si e o que é dito na enunciação". Essa dispersão do sujeito se deve ao fato de que o texto seria sempre uma dispersão de discursos diversos, de recortes do interdiscurso.

Em Semântica do Acontecimento, Guimarães afirma que interpretar uma forma linguística consiste em explicar como seu funcionamento faz parte da constituição do sentido do enunciado. Dizendo de outra maneira, considerar que uma forma funciona em um enunciado é considerar que ela funciona num texto, e saber dizer em que medida ela é constitutiva do sentido do texto. De acordo com o autor $(2005$, p. 7$)$

O sentido de um elemento linguístico tem a ver com o modo como este elemento faz parte de uma unidade maior ou mais ampla. Vê-se 
ao fazer este uso da relação integrativa, a despeito de Benveniste ter dito que ela não permitia passar do limite do enunciado, estou dizendo que há uma passagem do enunciado para o texto, que não é segmental. E esta é a relação de sentido.

O sentido que se produz no enunciado sobre o objeto ou o sujeito que enuncia é, portanto, resultado dos efeitos da enunciação. A contribuição dos estudos discursivos no pensamento de Guimarães leva-o a problematizar a visão benvenisteana de língua como sistema que apenas oferece marcas para a subjetividade. A reflexão de Guimarães (1996) volta-se ao processo que permite que determinadas marcas da língua signifiquem no discurso ao considerar que o as formas são, na língua, o resultado da história de seus funcionamentos na enunciação.

Levando-se em conta que o recorte desse artigo é o uso dos pronomes que instauram as pessoas no discurso e os efeitos de sentido produzidos, pode-se afirmar, a partir das proposições de Guimarães, que o uso que se faz de formas como eu ou nós, por exemplo, não é uma simples escolha do falante ou um mero uso do recurso que a língua oferece, mas uma possibilidade histórica da língua para tal forma de inscrição. A forma linguística que o sujeito emprega para falar de si, mais que inseri-lo no discurso, aponta os processos discursivos de constituição da posição que esse sujeito ocupa e dos efeitos que seu dizer desdobra. Em relação ao texto analisado, é possível compreender a locutora como um sujeito do discurso que produz, a partir do momento em que se descreve a posição assumida por ela em relação ao tema (velhice) e ao interlocutor (supostamente, o idoso). Essa posição é efeito de uma movimentação de memórias, ativadas ou silenciadas pela materialidade linguística do enunciado.

\section{A Instauração das Pessoas da Enunciação na Entrevista}

$\mathrm{Na}$ entrevista selecionada para análise, a organizadora do livro, Lúcia Ribeiro, é convocada a divulgar o livro "Um novo envelhecer é possível". O desenvolvimento da entrevista a leva a falar de si, da organização do livro e, ao final, a tecer alguns comentários de natureza técnica/avaliativa sobre o envelhecimento. 
O site Portal do Envelhecimento, onde a entrevista é divulgada, é mantido e alimentado por um grupo filiado ao OLHE - Observatório da Longevidade Humana e Envelhecimento. Os membros apresentamse na Seção 'Quem Somos' como “profissionais de diversas áreas, pesquisadores e professores, mestres e doutores, todos estudiosos do processo de envelhecimento na perspectiva do ser que envelhece e não unicamente que adoece". Essa filosofia frente ao envelhecimento "é o pressuposto para o desenvolvimento da contínua construção de uma "Cultura da Longevidade""6. Ainda na mesma seção, esclarecese o histórico do grupo: originou-se vinculado à PUC - Pontifícia Universidade Católica, extrapolou o meio acadêmico e passou a produzir "conteúdos com credibilidade e que atingem a população em geral, especialmente os que lidam com a população idosa".

Com base na apresentação feita, é possível imaginar que o perfil esperado de leitores do site seja pessoas idosas ou vinculadas a idosos. Essa expectativa sobre o público ajuda a inferir quem seriam os sujeitos dessa enunciação. Instaura-se como ego a organizadora do livro, Lúcia Ribeiro, que descreve a si mesma por meio da primeira pessoa, ora no singular (eu), ora no plural (nós). Isso pode ser observado em sequências como: "Nasci no dia 10 de junho de 1934, no Rio de Janeiro, onde moro. Sou socióloga, casada com Luiz Alberto Gomes de Souza" e "elaboramos uma reflexão conjunta, a partir da nossa experiência, abordando diversas dimensões do envelhecer".

A partir do imaginário sobre como se estabelecem entrevistas, supõe-se que a iniciativa parte da revista, que se coloca como o eu que entrevista e se dirige a um $t u$, o entrevistado. Tendo em vista a primazia conferida ao eu por Benveniste, seria possível considerar que, quem enuncia primeiro, estabelece-se como um eu e instaura o seu $t u$, que é a entrevistada. É ele, o site, quem pontua os assuntos abordados, por meio das perguntas, e conduz a conversa. Ao se instaurar como um dos sujeitos dessa enunciação, Lúcia interage com a voz do site Portal do Envelhecimento, com a qual reveza os turnos de fala. Entretanto, na fala do portal, não há marcação da forma linguística de primeira pessoa, o que ocorre na fala da entrevistada. Isso cria o efeito de apenas da entrevistada agir como o eu, tendo em vista que somente ela se apropria das formas linguísticas eu-nós nessa interação. 
Revezando-se na condição de locutores, tais vozes falam do ele, da terceira pessoa, que constitui o assunto. $\mathrm{O}$ foco da entrevista está no livro, cujo tema é o envelhecimento, o que faz ser convocado para a interpretação desse enunciado um terceiro sujeito desdobrado entre: aquele que vive a velhice, o idoso e aqueles que compartilharam a elaboração do livro. Isso pode ser observado em sequências como "Para apreender essa complexidade, decidimos abordá-la desde diversas dimensões: na social, indica transformações que possibilitam aos idosos uma melhor qualidade de vida", "O livro surgiu no meio desse processo: incluímos mais um texto do teólogo Leonardo Boff e os diversos depoimentos de idosos". O idoso constitui aquele de quem se fala é alguém que está fora da enunciação imediata.

Contudo, além disso, o idoso é, também, um dos leitores esperados para esse site. Ocorre, portanto, um desdobramento: na situação imediata de enunciação da entrevista, figura como o ele. Quando se considera que essa entrevista será veiculada e ele é um dos leitores esperados, torna-se um $t u$, ainda que virtual dessa enunciação. Como a voz que entrevista não é nomeada como tu da entrevistada, abre-se a possibilidade de, no imaginário, sobrepor a ela o idoso como interlocutor dessa enunciação. Apaga-se o $t u$ da enunciação imediata e abre-se a possibilidade de inferir o $t u$ da replicação do texto como interlocutor. Desdobrar-se em tu e em ele da enunciação, marca a importância do idoso na atribuição de sentido e na circulação desse texto, por isso problematiza-se a identificação da autora a ele como uma das possíveis formas de favorecer a aceitação/circulação do texto naquele veículo.

A entrevistada nomeia-se por meio da primeira pessoa, porém alterna a ocorrência dos pronomes eu e nós. No início da entrevista, enquanto mesclam-se questões sobre o livro com questões de cunho pessoal, ocorre a alternância, porém, a partir da terceira pergunta, ela utiliza somente o pronome nós. Há duas ocorrências do uso do pronome $e u$ : "A partir de uma inquietação pessoal, vinha partilhando reflexões e preocupações sobre as questões do envelhecer, com algumas amigas: Ney Paiva Chaves, Iza Guerra, Maria José Santos, com quem formei a equipe original" e "Nasci no dia 10 de junho de 1934, no Rio de Janeiro, onde moro. Sou socióloga, casada com Luiz Alberto Gomes de 
Souza", nas quais a socióloga fala de experiências vividas a partir de um foco de individualidade.

As situações em que nomeia a si como parte de um nós surgem ao falar da equipe que organizou o livro. Após nomear os integrantes do grupo, ela afirma "elaboramos uma reflexão conjunta, a partir da nossa experiência, abordando diversas dimensões do envelhecer" ou ainda "Ao analisar a situação social do idoso, incluímos a experiência de um setor específico, que são profissionais urbanos de classe média". Porém, com o avançar da entrevista, o uso do nós se torna mais diluído. Em sequências como "Conseguir aceitar subjetivamente a metamorfose que objetivamente está se dando em nós, e que, frequentemente, é mais visível para os outros do que para nós mesmos" ou em "É fundamental tomar consciência de nossa finitude, embora o tempo que nos resta seja imprevisível".

Assim como já havia problematizado Benveniste ao discutir a questão das pessoas do plural, estudos gramaticais mais recentes, como os de Neves (2000), apontam que existem variados usos para o pronome nós. Segundo a autora (2000, p. 527), ele "constitui tipicamente a soma do $e u+n \tilde{a} o-e u$. O não-eu pode corresponder a uma $2^{\mathrm{a}}$. ou a uma $3^{\mathrm{a}}$. pessoa, ou a ambas conjuntamente. Além disso, ele pode deslizar "para uma referência mais generalizada" (NEVES, p. 530). No início da entrevista, por conta da citação dos nomes dos colaboradores do livro, a referência de nós como eu + colegas era mais facilmente recuperável. Nessa leitura, a equipe que produziu o livro atua e o idoso, como público, fica excluído da situação de enunciação, tento em vista que figura apenas como o ele de quem se fala. Ao final da entrevista, contudo, essa referência não é mais retomada e, ao ficar distante, confere ao uso do pronome nós uma interpretação bastante ampla. Se compreendido como se referindo às pessoas de maneira geral, caberiam dentro dele a entrevistada e os colegas, a entrevistada, os colegas e os idosos ou qualquer pessoa.

\section{Das Pessoas da Enunciação ao Sujeito do Discurso}

Resumidamente, a instauração das pessoas do discurso nessa enunciação manifesta alguns fenômenos observáveis na forma 
linguística: a entrevistada, quando locutora, se nomeia como eu e como nós. Há um apagamento das marcas de $t u$ para o interlocutor, enquanto é ressaltado o papel do ele, o idoso. Observada a instauração das pessoas dessa enunciação, a partir das marcas formais do enunciado, propõese extrapolar as noções do aparelho formal da enunciação, seguindo o caminho aberto por Guimarães, o que implica problematizar a posiçãosujeito assumida pela entrevistada em relação aos idosos (seu público), bem como interrogar se a forma como se marcam as pessoas do discurso contribuem para uma identificação entre entrevistada e público.

Ao colocar a língua em funcionamento para tratar do envelhecimento e das questões a ele relacionadas são reativadas, do interdiscurso, inúmeras memórias sobre o idoso. Essas memórias envolvem, por exemplo, o imaginário de como era o idoso antes e como é hoje. Moraes (2001) constata uma variedade na produção de discursos sobre quem é o velho e o que é a velhice no Brasil. A autora destaca inúmeras dessas vivências como a velhice-pobre e desamparada, a terceira idade, a velhice ativa, saudável e que não apresenta idade, a que consome planos de saúde e medicamentos, os idosos que sustentam a si mesmos, a seus filhos e netos. Todos esses exemplos seriam indícios das múltiplas maneiras de envelhecer na contemporaneidade. $\mathrm{O}$ aumento do número de idosos conferiu visibilidade ao grupo. Isso permitiu a luta por direitos e reconhecimento, o que fomentou a emergência de enunciados em que esse sujeito seja representado de forma respeitosa e positiva. Porém, paralelamente a essa imagem de idoso, funciona (ainda e entre outras) uma memória que associa a velhice a coisas ruins, tais como doença, solidão e improdutividade. É compreensível que, quando a associação é à memória ruim, o sujeito não queira se identificar.

Segundo o Estatuto do Idoso, entram nessa faixa etária pessoas que tenham sessenta anos ou mais. Entretanto, a terceira idade é algo com que algumas pessoas se identificam e outras não, independentemente de suas idades. Isso prova que ser velho, assim como pertencer a qualquer outra faixa etária, é fazer parte de um sistema social, o qual se organiza a partir de práticas materializadas na linguagem. Assumir a posiçãosujeito de idoso implica lidar com essas demandas, demarcando um lugar para si em meio a essa teia de memórias que se concretizam e 
se atualizam na linguagem. Essas escolhas podem se materializar na língua, a partir de marcas formais.

A entrevistada, pela temática que discute, é instada a assumir uma posição-sujeito em relação à vivência da velhice e às memórias que a constituem. Além disso, outras coerções incidem sobre a posição-sujeito ocupada por Lúcia: ao ser entrevistada como a organizadora do livro sobre envelhecimento, ela assume o status de especialista legitimada a falar do assunto e, com isso, as contradições inerentes a essa condição. Assim como o que se pode recuperar do interdiscurso sobre a velhice, as memórias sobre a posição de especialista são contraditórias. Se, por um lado, muitos defenderam a experiência própria como forma de ganhar conhecimento de causa para falar sobre algo, por outro lado, alguns discursos (o científico, principalmente) propõem o distanciamento entre o especialista e seu objeto, como forma de garantir a objetividade da avaliação. Assumir uma posição-sujeito nesse enunciado implica para a locutora, Lúcia, equilibrar tais contradições, e essa ambivalência se materializa, entre outros elementos, pela forma como são referenciados locutor, interlocutor e assunto, no enunciado.

No início da entrevista, em uma das sequências em que a locutora nomina-se como eu, ela elenca os participantes do projeto do livro e afirma que o grupo se reuniu para discutir questões do envelhecimento. Isso se origina de uma inquietação assumida como da locutora e descrita como algo que surge da experiência dela, o que possibilita a inferência de que ela seja uma pessoa que passa por esse processo; todavia essa afirmação não é feita categoricamente, deixando aberta também a possibilidade de que o leitor suponha que ela trabalha/convive com idosos.

Na sequência, há uma ocorrência do pronome nós. O fato de citar as pessoas que participavam da equipe e depois utilizar o pronome nós, favorece a leitura de que o referente desse nós seja o grupo de colaboradores do livro. Assim como acontece com a autora, esse grupo não é descrito explicitamente como idoso, essa informação fica apenas implícita. Ocorre nesse processo de instauração da locutora, uma identificação muito sutil à ideia do envelhecimento e, consequentemente, ao sujeito idoso. Isso, por um lado, favorece a constituição de uma imagem de pesquisadora objetiva e, em contrapartida, distancia a 
imagem da entrevistada dos leitores idosos que esperavam ouvir palavras de alguém que viva o que eles vivem.

O emprego do pronome nós de forma mais ampla ocorre no final da entrevista e abre a possibilidade de interpretá-lo como uma indeterminação ou uma generalização do sujeito. Na sequência "É fundamental tomar consciência de nossa finitude, embora o tempo que nos resta seja imprevisível", por exemplo, a afirmação feita pode ser relacionada não só aos idosos, mas a qualquer ser humano. Essa construção, entretanto, não exclui o idoso do grupo e não o insere explicitamente. Em decorrência da possibilidade de remeter a qualquer pessoa, a interpretação desse pronome pode incluir a locutora da entrevista e/ou seus colegas autores, e/ou o entrevistador, e/ou a equipe do site e/ou os idosos. Desse modo, estar incluso na referência desse pronome não implica necessariamente identificarse à velhice e às memórias a ela relacionadas, ou seja, é possível assumir a posição-sujeito de parte do grupo sem assumir a posição de idoso.

Essas escolhas linguísticas materializam, na linguagem, uma posição que constitui a entrevistada como sujeito dessa enunciação. Tal posição, assim como as conflitantes memórias retomáveis sobre idosos, manifesta a contradição da vivência da velhice, ao implicitá-la em vez de assumi-la. Essa posição permite que o idoso se reconheça como parte do enunciado que interpreta e, em outro gesto, reconheça a existência desse enunciado como parte de si e da sua experiência. Esse vínculo, porém, deverá ser atribuído pela sua leitura, funciona como um efeito de sentido, pois, ao mesmo tempo em que permite a identificação, não a verbaliza categoricamente.

Em termos de adesão, a posição assumida pela entrevistada nem se compromete com a imagem do idoso e nem a renega: trabalha em uma tensão entre estar dentro e estar fora, fazer parte ou apenas observar. A suposta neutralidade demonstra um sujeito que se divide entre identificar-se como idoso ou não e a implicações disso para a sua imagem. Entre afirmar e sugerir, a escolha pela segunda opção demonstra, na língua, as marcas dessa tensão e uma tentativa de "juntar os pontos". Tal posicionamento parece vir ao encontro das coerções impostas pela condição social que ela ocupa, na medida em que permite 
a empatia dos idosos e assegura um razoável distanciamento que sustenta a posição de um especialista.

\section{CONSIDERAÇÕES FINAIS}

A proposta de análise embasada na Teoria da Enunciação de Benveniste volta-se, como apresentado, a descrever a instauração da subjetividade em enunciados a partir de elementos oferecidos pela língua para que isso ocorra. $\mathrm{Na}$ entrevista analisada, foi possível observar isso a partir da categoria de pessoa, problematizando como o trabalho com as formas linguísticas pode indicar processos discursivos nesse material.

Como é conveniente a uma entrevista, o entrevistador não se marca como eu mesmo quando enuncia. $\mathrm{O}$ que permite um foco maior no entrevistado, que se denomina $e u$ e fala de si. Na entrevista de Lúcia Ribeiro, contudo, a marca linguística de ego alterna a forma eu com a forma nós, levando em conta estudos que, como os de Benveniste, consideram que o nós é constituído do eu mais um não$e u$. Problematizou-se, no contexto dessa enunciação, quais pessoas poderiam ser convocadas a compor o sentido nós e quais efeitos de sentido derivam dessa leitura. $\mathrm{O}$ uso mais genérico do pronome tornou possível que, entre outras pessoas, o idoso, funcionasse como parte que compõe essa primeira pessoa do discurso.

Em termos de análise de discursos midiáticos, a junção do idoso à locutora pode sinalizar processos discursivo-enunciativos por meio das quais são produzidos efeitos de proximidade, de inclusão ou mesmo de exclusão. Em certa medida, no caso aqui analisado, a enunciação aproxima o provável leitor do texto, o que pode facilitar a circulação desse saber. Contudo, a identificação entre locutora e idoso é tênue, o que sugere uma posição-sujeito afetada por diferentes tensões, dividida, tal como apontou Guimarães (1996), entre o que se supunha saber sobre si e o que foi dito na enunciação.

Avançando um pouco mais nessa direção, ou seja, fazendo uma incursão nos estudos sobre subjetivação, em especial, aqueles derivados dos trabalhos de Michel Foucault, pode-se, em hipótese, afirmar que a fluidez da subjetivação da entrevistada no enunciado analisado mostra 
como os processos de subjetivação são variados e, ao mesmo tempo, singulares. Essa análise dá visibilidade ao fato de que, socialmente, não se tem uma identidade homogênea de idoso, o que leva o sujeito a trabalhar essa costura das memórias conhecidas, tentando retomar e identificar-se ao que é considerado positivo atualmente.

\section{IdENTIFying and Elderly as a Speaker: An EnUnciative Analysis}

\section{AbStRact}

The aim of the discussions presented in this article was to analyze the identification (or not) of a speaker with the subject-position of an elderly person. We selected an interview from the Portal do Envelhecimento (Aging Portal) website as the corpus of the analysis. In this interview, a book organizer describes her book-drafting process, whose theme focuses on issues related to aging. We based the analysis on the enunciative studies proposed by Benveniste (1989, 1995) and Guimarães (1989, 1995, 1996, 2005). This theoretical approach allowed us to observe how the enunciation was established in that interview. By observing the use of personal pronouns, we performed the linguistic analysis of this material. This enabled us to establish the interviewed author as the focus and, therefore, as the main speaker. As for the other people brought into this enunciation process, the interviewer was referred to as you and the elderly as he. In general, the analysis highlighted the following considerations: a) in the enunciator's speech, there is a deletion of the you and an alternation between the $I$ and the we, when referring to the first person; b) the use of the we, in some situations, joins the speaker to the group who helped to produce the book, and in others, it is not defined, allowing the interpretation of the he (the elderly) as included; c) such use of pronouns shows that the speaker builds just an implicit identification of the elderly in the subject-position.

KeYwords: Speaker, Elder, Enunciation, Subject-position.

\section{LA CONSTITUCIÓN DE UN LOCUTOR MAYOR: UNA ANÁLISIS ENUNCIATIVA}

\section{RESUMEN}

Las discusiones presentadas en este artículo poseen el objetivo de analizar la identificación (o no) de un locutor con la posición-sujeto mayor. Como corpus 
del análisis se eligió una entrevista que se reprodujo en el sitio "Portal do Envelhecimento" (Portal del Envejecimiento), en el cual la organizadora de un libro expone el trabajo de elaboración de la obra, cuya temática se centra en cuestiones relacionadas a la vejez. El análisis está basado en los Estudios Enunciativos, desde las propuestas de Benveniste $(1989,1995)$ y las de Guimarães $(1989,1995,1996,2005)$. Esta base teórica permitió observar como ocurre, a lo largo del texto de la susodicha entrevista, la instauración de las personas de la enunciación. Para esto, la entrada lingüística en este material se dio por la observación de los pronombres personales utilizados, los cuales han permitido establecer la autora que se entrevistó como foco y, por lo tanto, como locutora principal. En relación a las demás personas instauradas en ese proceso enunciativo, la entrevistadora se constituyó como tú y el mayor como él. De forma general, el análisis ha direccionado para las siguientes consideraciones: a) en el habla de la enunciadora, se borra el tú y hay una alternancia entre yo y nosotros para referirse a la primera persona; b) el uso de nosotros, en algunas situaciones, une la locutora al grupo que ha colaborado en la confección del libro y en otras es indeterminado, lo que permite la interpretación del él (mayor) como incluso; c) tal uso de los pronombres demuestra que la locutora construye una identificación solamente implícita a la posición-sujeto mayor.

Palabras Clave: Locutor, Mayor, Enunciación, Posición-Sujeto.

\section{NOTAS}

1 Disponível em: <http://europa.eu/legislation_summaries/employment and_social_policy/situation_in_europe/c10160_pt.htm>. Acesso em: 09 jan. 2013.

2 Disponível em:- $<$ http://webcache.googleusercontent.com/ search?q=cache:loeYGofRBx4J: www.ibge.gov.br/home/presidencia/noticias/ noticia_impressao.php $\% 3$ Fid_noticia\%3D1272+popula $\% \mathrm{C} 3 \% \mathrm{~A} 7 \% \mathrm{C} 3 \% \mathrm{~A}$ $3 \mathrm{o}+$ idosa + censo $+2010 \& \mathrm{~cd}=2 \& \mathrm{hl}=\mathrm{pt}-\mathrm{BR} \& \mathrm{ct}=\mathrm{clnk} \& \mathrm{gl}=\mathrm{br} \&$ source $=\mathrm{www}$. google.com.br>. Acesso em: 09 jan.2013. Anexa ao final do trabalho.

3 Tal problematização vem sendo desenvolvida, sob o viés discursivo por pesquisadores do GEF (Grupo de Estudos Foucaultianos) a partir de pesquisas diversas sobre os idosos e questões a eles relacionadas. 
4 Anexado ao final do artigo. Disponível em: $<$ http://www. portaldoenvelhecimento.org.br/> . Acesso em: 09 jan.2013.

5 Faz-se referência aos estudos linguísticos surgidos a partir da publicação do "Curso de Linguística Geral" (1969) de Ferdinand Saussure. Como é de conhecimento, tal proposta dividia a língua em langue e parole e propunha estudar a primeira (parte social e sistemática), enquanto deixava de lado a segunda (parte individual e variável). Juntamente com autores como Sapir, Bally, Bloomfield, Chomsky, entre outros, a proposta de Saussure faz parte da chamada Linguística Imanente, por focar os estudos na forma, com vistas a descrever sistemas linguísticos, sem abordar a subjetividade.

6 Disponível em: <http://portaldoenvelhecimento.org.br/quem-somos.html>. Acesso em: 14 jan. 2013.

\section{ANEXO}

\section{UM NOVO ENVELHECER É POSSÍVEL}

O livro que leva este título acaba de ser lançado, mas tem uma longa história: começou a ser pensado em uma cidade que se chama Guapimirim, há sete anos (2005), em uma reunião de profissionais que desejavam refletir sobre as experiências ao enfrentar o processo de envelhecer. $\mathrm{O}$ debate se estendeu desde então, entre reuniões e conversas (in)formais, e finalmente se concretizou na coletânea, da qual muitos participaram, publicada este ano pela editora Ideias \& Letras (www.ideiaseletras.com. br). A coletânea foi organizada pela socióloga Lúcia Ribeiro, do Rio de Janeiro. 11/12/2012 - por Texto: Guilherme Salgado Rocha. Fotos: arquivo pessoal na categoria 'Entrevista'

\section{Portal - Situe Guapimirim, por favor, que passou a ter grande importância em todo o processo de elaboração do livro. \\ Lúcia - Guapimirim é uma pequena cidade, no subúrbio do Rio de Janeiro, antes da subida da serra para Teresópolis. Foi lá que aconteceu o primeiro encontro, em 2005. A partir de uma inquietação pessoal, vinha partilhando reflexões e preocupações sobre as questões do envelhecer, com algumas amigas: Ney Paiva Chaves, Iza Guerra, Maria José Santos, com quem formei a equipe original. Com a participação de}


cerca de 30 pessoas - profissionais de setores médios urbanos do Rio de Janeiro e de São Paulo -, elaboramos uma reflexão conjunta, a partir da nossa experiência, abordando diversas dimensões do envelhecer. Depois do encontro, continuamos refletindo e debatendo. Em 2007, fizemos um novo seminário, na Barra da Tijuca, no Rio de Janeiro, com um grupo menor, e em 2011 mais um encontro, na Fazenda do Cedro, perto de Petrópolis. O livro surgiu no meio desse processo: incluímos mais um texto do teólogo Leonardo Boff e os diversos depoimentos de idosos. E depois o processo para conseguir editora e efetivamente ter o livro publicado foi longo.

\section{Portal - Por favor, sempre perguntamos os dados pessoais.}

Lúcia - Nasci no dia 10 de junho de 1934, no Rio de Janeiro, onde moro. Sou socióloga, casada com Luiz Alberto Gomes de Souza. Temos três filhos e seis netos.

\section{Portal - O grupo abordou a complexidade do tema sob diversos ângulos, correto?}

Lúcia - Para apreender essa complexidade, decidimos abordála desde diversas dimensões: na social, indica transformações que possibilitam aos idosos uma melhor qualidade de vida, apesar do persistente preconceito; na físico-biológica, ressalta mudanças sempre permeadas pela subjetividade; na psicoanalítica, mostra a coexistência de reações de medo e tristeza pelas perdas com a criação de elaborações criativas; e na filosófico-espiritual, enfatiza o polo da interioridade, com sua possibilidade de crescimento indefinido, vendo a morte como a passagem para uma vida plena.

\section{Portal - Ao lado dos textos mais analíticos, o livro inclui testemunhos... \\ Lúcia - São depoimentos preciosos de pessoas que conhecem a velhice por dentro, como Marialzira Perestrello, Luis Viegas, Rose Marie Muraro e Yolanda Bettencourt, e de uma criança, Francisco Oromi R. de Souza, vendo a velhice de longe. Finalmente, o livro tem a dimensão poética, do filósofo e poeta Rogério Luz.}




\section{Portal - Você falava da importância de reunir experiências distintas...}

Lúcia - Ao analisar a situação social do idoso, incluímos a experiência de um setor específico, que são profissionais urbanos de classe média, pertencentes à geração que nasceu nas décadas de 30/40. Isso nos possibilitou aprofundar a reflexão a partir de uma prática concreta e desde uma perspectiva que encara o processo do envelhecer de forma dialética: sem negar as perdas e as limitações reais, que não podem ser maquiadas, descobre os espaços positivos que se abrem nessa fase. A partir dessa perspectiva, que assume perdas e ganhos, identificamos alguns desafios, que se colocam para a nossa geração, no mundo atual.

\section{Portal - Quais são esses desafios?}

Lúcia - Conseguir aceitar subjetivamente a metamorfose que objetivamente está se dando em nós, e que, frequentemente, é mais visível para os outros do que para nós mesmos, reconhecendo a necessidade do cuidado, sem esquecer a conquista permanente da autonomia possível. Saber dialogar com as gerações mais jovens, abertos às suas perspectivas e descobertas, mas sem abrir mão de uma visão crítica. Assumir um compromisso ativo e participante em grupos, sejam eles profissionais, religiosos, culturais ou de qualquer outro tipo, e sentir-se parte de um todo, assumindo sua responsabilidade pessoal, a partir de nossas possibilidades atuais.

\section{Portal - Há no livro discussões acerca da sexualidade.}

Lúcia - Esse é outro desafio: não abrir mão da criatividade para inventar novas formas de viver a sexualidade, baseada na libido, no afeto e no que cada um julga mais adequado às suas próprias condições. E discutimos ainda que é essencial descobrir a riqueza de construir a solidão, como um momento de encontro consigo mesmo, além de se reconciliar com o passado, com seus feitos e sobretudo com as omissões e falhas, hoje já irrecuperáveis, e descobrir a função social do resgate da memória, com a lucidez de distinguir o que ainda pode ser enriquecedor, no momento atual, do que precisa ser definitivamente superado. 


\section{Portal - E sobre a espiritualidade?}

Lúcia - É fundamental tomar consciência de nossa finitude, embora o tempo que nos resta seja imprevisível: somente quando integramos e aceitamos a morte vivemos plenamente a vida. Temos que aprofundar a vida interior e a espiritualidade - próprias de qualquer ser humano, independentemente de ter ou não opção religiosa -, questionando o sentido da vida e reconhecendo nela a dimensão do Mistério.

\section{Portal - Não são desafios fáceis.}

Lúcia - Não, não são. Mas esses e outros desafios permeiam a travessia das águas, ora serenas, ora turbulentas - mas sempre instigantes -, da sexta ou sétima década da vida. Nossa geração viveu tempos marcados pela esperança de transformar o mundo, expressa em processos políticos, culturais e sociais. Viveu ainda os momentos de ocaso, de revezes, de desilusão. Mas para muitos de nós, que participamos ativamente desses processos, o compromisso com a transformação social, em seus mais diversos níveis, continua vivo. E no atual momento da vida, acreditamos que "um outro envelhecer é possível", se nos assumimos como sujeitos ativos dessa etapa, tornando-a uma experiência socialmente fecunda e pessoalmente feliz.

\section{REFERÊNCIAS}

BARBISAN, L. B. O conceito de enunciação em Benveniste e em Ducrot. Revista Letras, Santa Maria, RS: Programa de Pós Graduação em Letras PPGL/UFSM, n. 33, jul./dez., p. 23-35, 2006. Disponível em: <http://w3.ufsm. br/revistaletras/artigos_r33/revista33_3.pdf $>$. Acesso em: 6 jul. 2013.

BENVENISTE, E. Problemas de Lingüistica Geral I. 4. ed. Campinas: Pontes, 1995.

.O aparelho formal da enunciação. In: Problemas de Lingüistica Geral II. 3. ed. São Paulo: Pontes, 1989.

FLORES, V. do N.; SILVA, S.; LICHTENBERG, S.; WEIGERT, T. Enunciação e gramática. São Paulo: Contexto, 2008.

GUIMARÃES, E. Língua e Enunciação. Caderno de Estudos Linguísticos. Campinas (30): 99-103 Jan/Jun. 1996. 
. Os limites do sentido. Um estudo histórico e enunciativo da linguagem. Campinas: Pontes, 1995.

. Enunciação e história. In: GUIMARÃES, Eduardo (Org.). História e sentido na linguagem. Campinas. Pontes, 1989.

. Semântica do acontecimento: um estudo enunciativo da designação. 2. ed. Campinas: Pontes, 2005.

INSTITUTO BRASILEIRO DE GEOGRAFIAE ESTATÍSTICA. Disponível em: $<$ http://webcache.googleusercontent.com/search?q=cache:loeYGofRBx4J:www. ibge.gov.br/home/presidencia/noticias/noticia_impressao.php\%3Fid_noticia $\% 3 \mathrm{D} 1272+$ popula $\% \mathrm{C} 3 \% \mathrm{~A} 7 \% \mathrm{C} 3 \% \mathrm{~A} 3 \mathrm{o}+\mathrm{idosa}+$ censo $+2010 \& \mathrm{~cd}=2 \& \mathrm{hl}=\mathrm{pt}-$ BR\&ct $=$ clnk\&gl $=$ br\&source $=$ www.google.com.br $>$.

MORAES, A. O corpo no tempo: velhos envelhecimentos. In PRIORI, M . Del. AMANTINO. M.(Org.) História do Corpo no Brasil. São Paulo: Unesp, 2011.

NEVES, M. H. M. Gramática de Usos do Português. São Paulo: Ed. da Unesp, 2000.

POSSENTI, S. Discurso, estilo e subjetividade. São Paulo: Martins Fontes, 1988.

SAUSSURE, F. Curso de Linguística Geral. Tradução Antônio Chelini, José. Paulo Paes e Izidoro Blikstein. São Paulo: Cultrix, 1969.

ZANDWAIS, A. Demarcando relações entre enunciado e enunciação a partir de diferentes leituras. Interfaces. Guarapuava, v.2 n. 1, jul. 2011. p.14-22.

Submetido em 16 de setembro de 2014

Aceito em 14 de abril de 2015

Publicado em 21 de dezembro de 2015 
